\title{
The effect of weight, body mass index, age, sex, and race on plasma concentrations of subcutaneous sumatriptan: a pooled analysis
}

This article was published in the following Dove Press journal:

Clinical Pharmacology:Advances and Applications

I September 2016

Number of times this article has been viewed

\author{
Sagar Munjal' \\ Anirudh Gautam² \\ Alan M Rapoport ${ }^{3}$ \\ Dennis M Fisher ${ }^{4}$ \\ 'Department of Neurology Clinical \\ Development and Medical Affairs, \\ Dr. Reddy's Laboratories Ltd, \\ Princeton, NJ, USA; ${ }^{2}$ Pharmacokinetics, \\ Modeling and Simulation \& Bioanalysis, \\ Dr. Reddy's Laboratories Ltd, \\ Hyderabad, India; ${ }^{3}$ Department of \\ Neurology, The David Geffen School \\ of Medicine, University of California, \\ Los Angeles, Los Angeles, ${ }^{4} \mathrm{P}$ Less Than, \\ San Francisco, CA, USA
}

Objective/background: Factors such as body size (weight and body mass index [BMI]), age, sex, and race might influence the clinical response to sumatriptan. We evaluated the impact of these covariates on the plasma concentration $(\mathrm{Cp})$ profile of sumatriptan administered subcutaneously.

Methods: We conducted three pharmacokinetic studies of subcutaneous sumatriptan in 98 healthy adults. Sumatriptan was administered subcutaneously (236 administrations) as either DFN-11 3 mg, a novel $0.5 \mathrm{~mL}$ autoinjector being developed by Dr. Reddy's Laboratories; Imitrex ${ }^{\circledR}$ (Sumatriptan) injection $3 \mathrm{mg}$ or $6 \mathrm{mg}(6 \mathrm{mg} / 0.5 \mathrm{~mL})$; or Imitrex STATdose $4 \mathrm{mg}$ or $6 \mathrm{mg}(0.5 \mathrm{~mL})$. Blood was sampled for 12 hours to determine sumatriptan $\mathrm{Cp}$. Maximum $\mathrm{Cp}\left(\mathrm{C}_{\max }\right)$, area under the curve during the first 2 hours $\left(\mathrm{AUC}_{0-2}\right)$, and total area under the curve $\left(\mathrm{AUC}_{0-\infty}\right)$ were determined using noncompartmental methods. Post hoc analyses were conducted to determine the relationship between these exposure metrics and each of body weight, BMI, age, sex, and race (categorized as white, black, or others).

Results: Both weight and BMI correlated negatively with each exposure metric for each treatment group. Across all treatment groups, $\mathrm{AUC}_{0-2}$ for subjects with $\mathrm{BMI}$ less than or equal to median value was 1.03-1.12 times the value for subjects with BMI more than median value. For subjects with BMI less than or equal to median value receiving DFN-11, median $\mathrm{AUC}_{0-2}$ was slightly less than that for subjects with BMI more than median value receiving Imitrex $4 \mathrm{mg}$ and larger than that for subjects with BMI more than median value receiving Imitrex $3 \mathrm{mg}$. Results were similar for the other exposure metrics and for weight. Exposure was higher in women than in men, which can be attributed in part to differences in weight. There was no relationship between exposure and age. For DFN-11, $\mathrm{AUC}_{0-2}$ and $\mathrm{AUC}_{0-\infty}$ were lower in nonwhites compared with whites; the ratio of median values was 0.84 and 0.89 , respectively. A similar, nonstatistically significant, trend was observed in the other products (ratio of median values ranging from 0.84 to 0.89 ).

Conclusion: Weight and BMI appear to be important covariates for sumatriptan exposure: subjects with lower values for either metric of body size have higher systemic exposure compared with subjects with higher values. Additional studies are required to determine if doses of subcutaneous sumatriptan may be adjusted based on BMI for comparable efficacy and a potentially improved tolerability profile.

Keywords: sumatriptan plasma concentration, migraine, body size, BMI, obesity, age, sex, race

\section{Introduction}

Migraine is a chronic, disabling neurological disorder with episodic clinical findings of headache, often associated with nausea and vomiting. In the US, $\sim 17 \%$ of women and $6 \%$ of men experience migraine. ${ }^{1}$ Sumatriptan is one of the most commonly used
Department of Neurolog Clinica

Development and Medical Affairs,

Dr. Reddy's Laboratories Ltd,

107 College Road East, Princeton, NJ 08540, USA

Tel + I 6093759083

Email smunjal@drreddys.com 
triptans for treatment of migraine attacks. Oral, intranasal (IN), and subcutaneous (SC) formulations of sumatriptan are approved by the Food and Drug Administration and are marketed in the US and several other countries. ${ }^{2-4}$ SC sumatriptan has a better efficacy profile than oral and IN sumatriptan products..$^{2-4}$ Absorption is more rapid with SC administration (time to reach maximum observed [peak] plasma concentration $\left[\mathrm{t}_{\text {max }}\right.$ ] for SC Imitrex ${ }^{\circledR}$ (Sumatriptan) is 12 minutes [range: 5-20 minutes]), significantly shorter than that for the oral (2-2.5 hours) ${ }^{2-4}$ and nasal routes (range: 60-90 minutes).$^{5}$ As a result, onset of action with SC sumatriptan (10 minutes) is faster than that with IN (30-45 minutes) or oral (45-60 minutes) delivery. ${ }^{2-4}$ There are several published pharmacokinetic (PK) studies for sumatriptan; however, few of these examine whether sumatriptan $\mathrm{PK}$ metrics (ie, $\mathrm{C}_{\text {max }}$ [maximum plasma concentration $\{\mathrm{Cp}\}]$ and AUC [area under the $\mathrm{Cp}$ vs time curve]) are affected by covariates such as weight, body mass index (BMI), age, sex, and race. In addition, sample size for many of these studies is small.

Currently, SC sumatriptan is available in $4 \mathrm{mg}$ and $6 \mathrm{mg}$ dosage forms (Imitrex STATdose, $0.5 \mathrm{~mL}$ ) and as an injectable solution (Imitrex injection, $6 \mathrm{mg} / 0.5 \mathrm{~mL}$ ). A low-dose (3 mg) sumatriptan product for SC injection, known as DFN11 (ZEMBRACETMSymTouch ${ }^{\mathrm{TM}}$, Dr. Reddy's Laboratories, Hyderabad, Telangana, India), is now approved for sale in the US. DFN-11 is a single-dose, $0.5 \mathrm{~mL}$ prefilled syringe as a ready-to-use disposable autoinjector. Efficacy of this $3 \mathrm{mg}$ autoinjector is expected to be same as existing sumatriptan injection $3 \mathrm{mg}$ products.

We conducted three clinical pharmacology studies (unpublished) to support a PK bridge between DFN-11 and several Imitrex products; data from these studies were pooled as the target populations and study methodologies were similar. To understand the impact of covariates on systemic exposure of sumatriptan, we examined the relationships between sumatriptan PK metric for each product and each of weight, BMI, age, sex, and race. Results of this analysis could provide insights into treatment outcomes. In addition, we evaluated whether subsets of subjects who received DFN$113 \mathrm{mg}$ have systemic exposure comparable to that in subsets of subjects who received larger doses of Imitrex.

\section{Methods}

We conducted three PK studies of SC sumatriptan in 98 healthy adults. The data from three studies were combined for pooled data analysis. The protocols were approved by the Chesapeake Research Review, Inc., Institutional Review Board, and the studies were conducted in compliance with good clinical practice at Celerion Research (Tempe, AZ and Lincoln, NE). Before the studies began, their nature was explained to the subjects, and subjects provided written informed consent. All studies used a single-dose, open-label, randomized crossover design to determine relative bioavailability following SC administration of sumatriptan succinate in healthy, fasted adults. The randomization sequences were generated by Celerion as per their Standard Operating Procedure. Each study included DFN$11(3 \mathrm{mg} / 0.5 \mathrm{~mL})$ vs either Imitrex injection $(3 \mathrm{mg} / 0.25 \mathrm{~mL}$ or $6 \mathrm{mg} / 0.5 \mathrm{~mL})$ or Imitrex STATdose system $(4 \mathrm{mg} / 0.5 \mathrm{~mL}$ or $6 \mathrm{mg} / 0.5 \mathrm{~mL}$ ). All three studies were conducted from July 2014 to February 2015. Brief descriptions of the three unpublished studies are as follows: study 001 (DFN-11-CD-001) was a two-way crossover study comparing DFN-11 with Imitrex injection $3 \mathrm{mg}$; subjects were randomized to one of two treatment sequences. Study 002 (DFN-11-CD-002) was a three-way crossover study that compared DFN-11 with Imitrex injection $3 \mathrm{mg}$ and $6 \mathrm{mg}$; subjects were randomized to one of six treatment sequences. Study 003 (DFN-11-CD-003) was a three-way crossover study comparing DFN-11 with Imitrex $4 \mathrm{mg}$ STATdose system and $6 \mathrm{mg}$ STATdose system; subjects were randomized to one of six treatment sequences. For all three studies, in each period, a single dose was administered SC over $\sim 5$ seconds. PK samples were obtained predose and at 5 minutes, 10 minutes, 15 minutes, 20 minutes, 30 minutes, 1 hour, 1.5 hours, 2 hours, 3 hours, 4 hours, 6 hours, 8 hours, 10 hours, and 12 hours postdose. Subjects were confined from 8 hours before the first dose through the last sample after the final dose. Doses were separated by at least 2 days.

Cps of sumatriptan were determined using high-performance liquid chromatography with mass spectrometric detection assay, sensitive to $0.5 \mathrm{ng} / \mathrm{mL}$. PK parameters for each dosing session were determined using noncompartmental methods with WinNonlin Version 6.3 (Certara, St Louis, MO, USA) or SAS Version 9.3 (SAS Institute Inc., Cary, NC, USA). The following exposure parameters were determined:

1. $\mathrm{C}_{\max }$ : the maximum measured $\mathrm{Cp}$, determined by examination of the data.

2. $\mathrm{AUC}_{0-2}$ : area under the $\mathrm{Cp}$ vs time curve from the time of drug administration to the 2-hour sample.

3. $\mathrm{AUC}_{0-\infty}$ : area under the concentration-time curve from the time of drug administration extrapolated to infinity. $\mathrm{AUC}_{0-\infty}$ is calculated as the sum of $\mathrm{AUC}_{0-\mathrm{t}}$ (where $\mathrm{t}$ is the last measured nonzero concentration) plus the ratio of the last measurable $\mathrm{Cp}$ to the elimination rate constant.

AUCs were calculated by the linear trapezoidal method.

Graphics were prepared to examine the relationship between each of $\mathrm{AUC}_{0-2}, \mathrm{AUC}_{0-\infty}$, and $\mathrm{C}_{\max }$ and the following covariates: weight $(\mathrm{kg}), \mathrm{BMI}\left(\mathrm{kg} / \mathrm{m}^{2}\right)$, age (years), sex, and 
race (categorized as white, black, or other [two subjects listed as "multiple" race were characterized as "other"]). For continuous covariates, the relationship between each metric and covariate was evaluated by linear regression -and a smoother (Supersmoother, Stanford, CA, USA). In addition, the median value for each continuous covariate (weight: $72.2 \mathrm{~kg}$; BMI: $26.33 \mathrm{~kg} / \mathrm{m}^{2}$; and age: 30.5 years) was identified, and the median value for the exposure metric for subjects below and above that median covariate value was determined; the ratio of these values is reported. For example, we compared exposure metrics for subjects weighing $>72.2 \mathrm{~kg}$ with those weighing less. For categorical covariates, the mean for each group was identified; groups were compared by $t$-test. The ratio of median values for female/male and non-white/white was determined. In addition, we conducted multiple regression analyses including each of weight or BMI plus either race (Caucasian vs non-Caucasian) or sex (race and sex included in the model as factors) to determine whether race or sex contributed to differences in exposure after accounting for body size.

\section{Safety}

Subjects were monitored for injection site reactions including pain, tenderness erythema/redness, and induration/swelling before dosing and at 6 hours and 12 hours after study drug administration in all periods.

\section{Results}

\section{Subject disposition}

Demographics characteristics are summarized in Table 1. All subjects were healthy and none used tobacco. One subject in Study 001 was found to be pregnant before Period 2 and was discontinued from the study. In Study 001, an incorrect procedure was applied for injection of Imitrex

Table I Demographic characteristics of the subjects in the three studies

\begin{tabular}{|c|c|c|c|}
\hline \multirow[t]{2}{*}{ Metric } & \multicolumn{3}{|l|}{ Study } \\
\hline & $001(\mathrm{~N}=26)$ & $002(\mathrm{~N}=36)$ & $003(N=36)$ \\
\hline $\begin{array}{l}\text { Sex (male/ } \\
\text { female) }\end{array}$ & $13 / 13$ & $17 / 19$ & $16 / 20$ \\
\hline Age (years) & $29.1(21-45)$ & $31.7(18-45)$ & $32.0(18-45)$ \\
\hline Weight (kg) & $78.3(47.7-1 \mid 3.2)$ & $73.4(49.3-109.6)$ & $74.8(51.3-116.5)$ \\
\hline Height (cm) & $169.9(151-193)$ & $166.5(151-184)$ & $166.7(153-188)$ \\
\hline BMI $\left(\mathrm{kg} / \mathrm{m}^{2}\right)$ & $27.0(19.2-34.8)$ & $26.4(19.6-34.6)$ & $26.7(19.8-33.8)$ \\
\hline \multicolumn{4}{|l|}{ Race } \\
\hline White & 21 & 31 & 31 \\
\hline Black & 3 & 5 & 2 \\
\hline Other & 2 & 0 & 4 \\
\hline
\end{tabular}

Note: Values for sex and race are counts; for the other metrics, values are mean (range).

Abbreviation: BMI, body mass index.
$3 \mathrm{mg}$; as a result, data from those sessions were excluded from the PK analysis. All remaining sessions were included in the PK analyses; all sessions were included in safety analyses. Thus, the total number of sessions included in the PK analysis was 97 for DFN-11, 35 for Imitrex injection $3 \mathrm{mg}, 36$ for Imitrex STATdose $4 \mathrm{mg}$, and 68 for Imitrex STATdose $6 \mathrm{mg}$. For one session with DFN-11, $\mathrm{AUC}_{0-2}$ could not be determined due to a missing sample at 2 hours; however, $\mathrm{AUC}_{0-\infty}$ could be determined since $\mathrm{t}_{\max }$ was much earlier than 2 hours.

\section{Effect of weight}

For each treatment group, increasing weight was associated with decreasing sumatriptan exposure (Figures 1-3 and Table 2) for all three metrics $(P<0.003$ [linear regression] for each treatment group within each metric). Across all treatment groups, $\mathrm{AUC}_{0-2}$ for subjects weighing less than or equal to median weight was $\sim 1.2$ times the value for subjects with weight more than median value. For subjects with weight less than or equal to median value receiving DFN-11, median $\mathrm{AUC}_{0-2}$ was similar to that for subjects with weight more than median value receiving Imitrex $4 \mathrm{mg}$ and larger than that for subjects with weight more than median value receiving Imitrex $3 \mathrm{mg}$. $\mathrm{AUC}_{0-\infty}$ for subjects with weight less than or equal to median value was 1.12-1.19 times the value for subjects with weight more than median value. For subjects with weight less than or equal to median value receiving $\mathrm{DFN}-11$, median $\mathrm{AUC}_{0-\infty}$ was slightly less than that for subjects with weight more than median value receiving Imitrex $4 \mathrm{mg}$ and markedly larger than that for subjects with weight less than or equal to median value receiving Imitrex $3 \mathrm{mg}$. $\mathrm{C}_{\max }$ for subjects with weight less than or equal to median value was $\sim 1.18-1.30$ times the value for subjects with weight more than median value. For subjects with weight less than or equal to median value receiving DFN-11, median $\mathrm{C}_{\text {max }}$ was slightly more than that for subjects with wieght more than median value receiving Imitrex $4 \mathrm{mg}$ and markedly larger than that for subjects with weight more than median value receiving Imitrex $3 \mathrm{mg}$.

In the multiple regression analyses, after incorporating the effect of weight, $\mathrm{C}_{\max }$ for DFN-11 was $5.8 \mathrm{ng} / \mathrm{mL}$ higher in women and $\mathrm{AUC}_{0-2}$ for DFN-11 was $3.0 \mathrm{ng} / \mathrm{mL} \mathrm{h}$ higher in women (Table 3). After incorporating the effect of weight, $\mathrm{AUC}_{0-2}$ was $3.3 \mathrm{ng} / \mathrm{mL} \mathrm{h}$ lower in non-Caucasians with DFN-11 and $6.1 \mathrm{ng} / \mathrm{mL}$ lower with Imitrex $4 \mathrm{mg}$. $\mathrm{AUC}_{0-\infty}$ was $3.6 \mathrm{ng} / \mathrm{mL} \mathrm{h}$ lower with DFN-11 and $9.5 \mathrm{ng} / \mathrm{mL} \mathrm{h}$ lower with Imitrex $4 \mathrm{mg}$ (Table 4). 

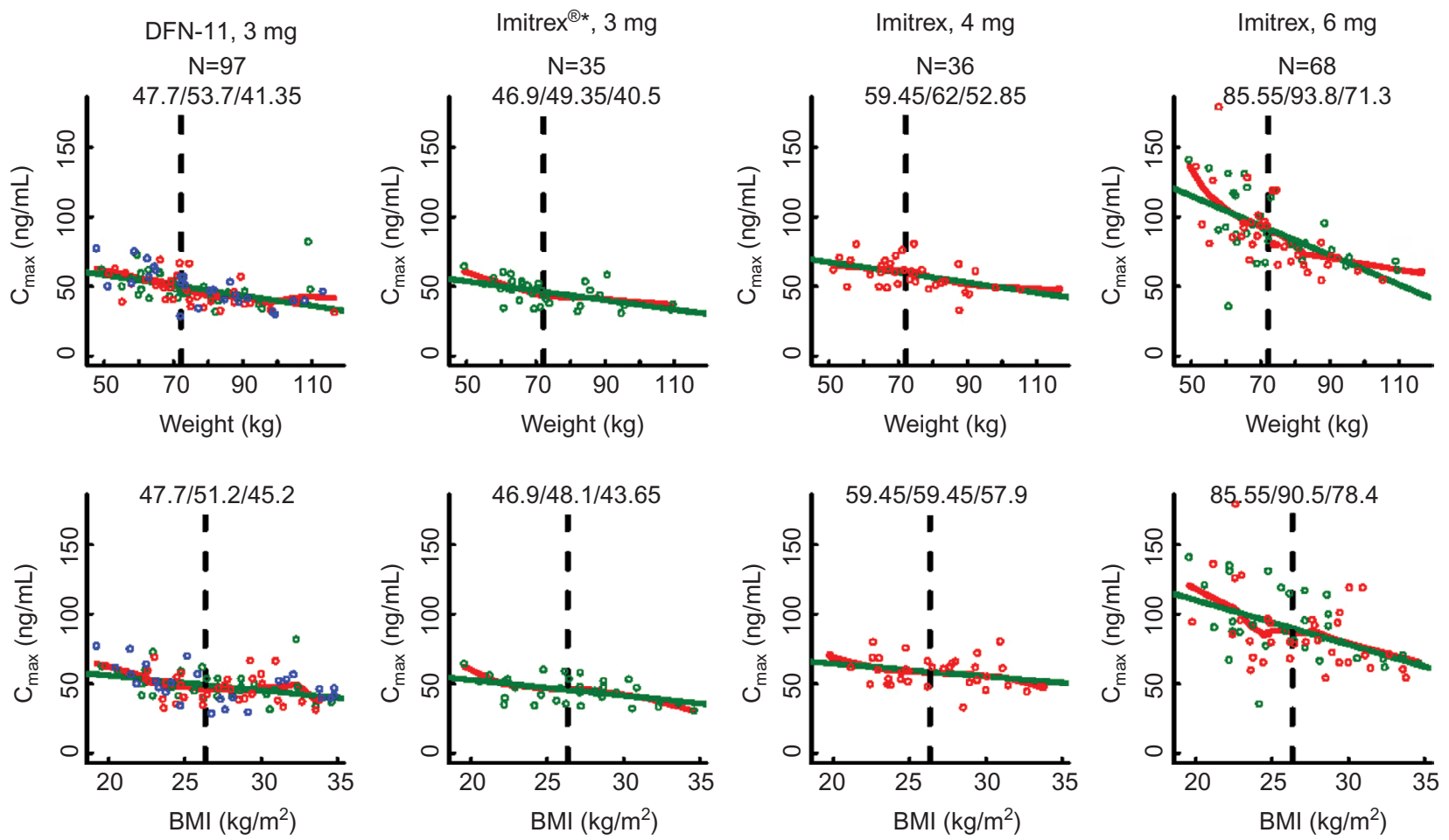

Figure I Values for $\mathrm{C}_{\max }$ are displayed against weight (top) and BMI (bottom) for each treatment group.

Notes: Colors indicate study (00I: blue; 002: green; and 003: red). A linear regression (green line) and a smoother (Supersmoother, red line) are displayed. Median values for all subjects, those with weight less than or equal to median value or BMI, and those with weight or BMI more than median value are displayed. *Generic name: Sumatriptan. Abbreviations: $\mathrm{BMI}$, body mass index; $\mathrm{C}_{\max }$, maximum plasma concentration.
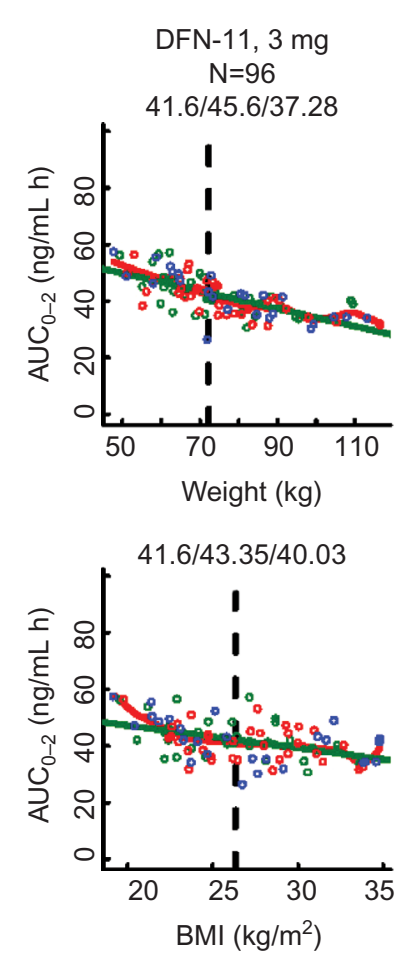
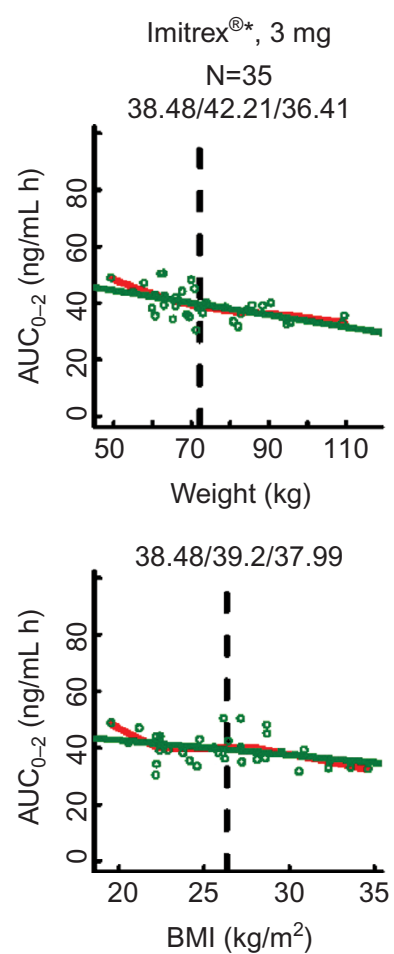
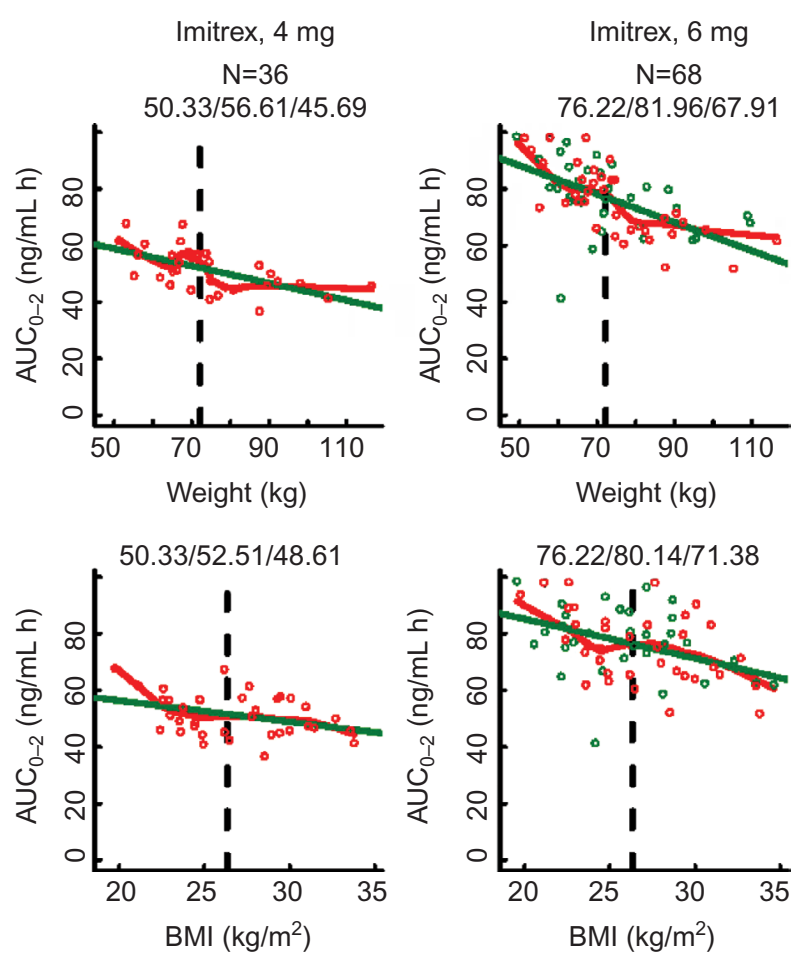

Figure 2 Values for $\mathrm{AUC}_{0-2}$ are displayed against weight (top) and BMI (bottom) for each treatment group.

Notes: Colors indicate study (00I: blue; 002: green; and 003: red). A linear regression (green line) and a smoother (Supersmoother, red line) are displayed. Median values for all subjects, those with weight less than or equal to median value or BMI, and those with median weight or BMI more than median value are displayed. *Generic name: Sumatriptan. Abbreviations: AUC, area under the curve; BMI, body mass index. 

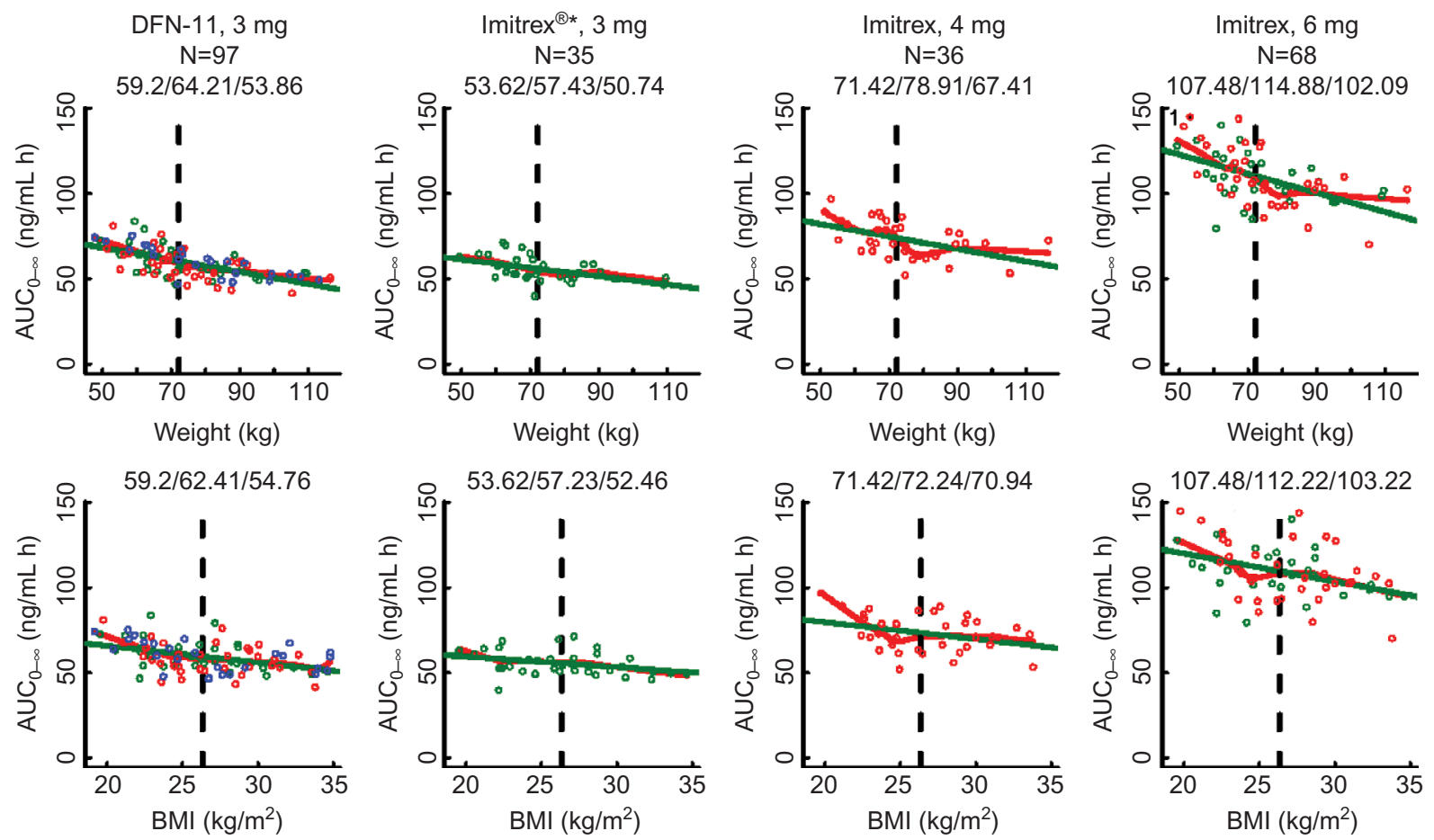

Figure 3 Values for $\mathrm{AUC}_{0-\infty}$ are displayed against weight (top) and BMI (bottom) for each treatment group.

Notes: Colors indicate study (00I: blue; 002: green; 003: red). A linear regression (green line) and a smoother (Supersmoother, red line) are displayed. Median values for all subjects, those with weight less than or equal to median value or BMI, and those with median weight or BMI more than median value are displayed. *Generic name: Sumatriptan. Abbreviations: AUC, area under the curve; BMI, body mass index.

Table 2 Effect of weight on systemic exposure to sumatriptan

\begin{tabular}{|c|c|c|c|c|}
\hline \multirow[t]{2}{*}{ Exposure metric } & \multirow[t]{2}{*}{ DFN-I I 3 mg } & \multicolumn{3}{|l|}{ Imitrex ${ }^{\circledR *}$} \\
\hline & & $3 \mathrm{mg}$ injection & 4 mg STATdose & $6 \mathrm{mg}$ STATdose or injection \\
\hline $\mathrm{AUC}_{0-2}(\mathrm{ng} / \mathrm{mL} \mathrm{h})$ & $45.60 / 37.28^{a}$ & $42.21 / 36.4 I^{a}$ & $56.61 / 45.69^{a}$ & $81.96 / 67.91^{a}$ \\
\hline$A \cup C_{0-\infty}(n g / m L h)$ & $64.21 / 53.86^{\mathrm{a}}$ & $57.43 / 50.74^{\mathrm{a}}$ & $78.91 / 67.4 I^{a}$ & $114.88 / 102.09^{a}$ \\
\hline $\mathrm{C}_{\max }(\mathrm{ng} / \mathrm{mL})$ & $53.70 / 41.35^{\mathrm{a}}$ & $49.35 / 40.50^{\mathrm{a}}$ & $62.00 / 52.85^{\mathrm{a}}$ & $93.80 / 71.20^{\mathrm{a}}$ \\
\hline
\end{tabular}

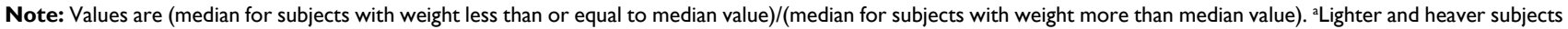
differ $(P<0.05)$ by $t$-test. *Generic name: Sumatriptan.

Abbreviations: $A \cup C$, area under the curve; $C_{\max }$, maximum plasma concentration.

Table 3 Additional effect of sex in regression models including weight or BMI (limited to those analyses for which the effect of sex was statistically significant)

\begin{tabular}{|c|c|c|c|c|c|c|c|}
\hline Weight/BMI & $\begin{array}{l}\text { Exposure } \\
\text { metric }\end{array}$ & Treatment & Intercept & $\begin{array}{l}\text { Coefficient } \\
\text { (weight/BMI) }\end{array}$ & Coefficient (sex) & $P$ (weight/BMI) $^{\mathrm{b}}$ & $P(\operatorname{sex})^{b}$ \\
\hline Weight & $\mathrm{C}_{\max }$ & DFN-II, $3 \mathrm{mg}$ & 64.407 & -0.249 & 5.827 & 0.0025 & 0.0190 \\
\hline Weight & $A \cup C_{0-2}$ & DFN-II, $3 \mathrm{mg}$ & 59.253 & -0.251 & 2.966 & $<0.0001$ & 0.0236 \\
\hline BMI & $\mathrm{C}_{\max }$ & DFN-II, $3 \mathrm{mg}$ & 65.025 & -0.786 & 8.956 & 0.0015 & $<0.0001$ \\
\hline BMI & $\mathrm{C}_{\max }$ & Imitrex, 4 mg & 65.317 & -0.447 & 8.925 & 0.3515 & 0.0134 \\
\hline BMI & $\mathrm{C}_{\max }$ & Imitrex, 6 mg & 150.740 & -2.611 & 14.813 & 0.0008 & 0.0093 \\
\hline BMI & $\mathrm{AUC}_{0-2}$ & DFN-II, $3 \mathrm{mg}$ & 54.519 & -0.600 & 6.510 & $<0.0001$ & $<0.0001$ \\
\hline BMI & $\mathrm{AUC}_{0-2}$ & Imitrex, 3 mg & 49.180 & -0.443 & 3.671 & 0.0503 & 0.0333 \\
\hline BMI & $\mathrm{AUC}_{0-2}$ & Imitrex, 4 mg & 57.542 & -0.377 & 6.974 & 0.2488 & 0.0050 \\
\hline BMI & $\mathrm{AUC}_{0-2}$ & Imitrex, 6 mg & 99.450 & $-1.05 \mid$ & 8.648 & 0.0050 & 0.0020 \\
\hline BMI & $A \cup C_{0-\infty}$ & DFN-II, $3 \mathrm{mg}$ & 76.903 & -0.780 & 6.113 & 0.0001 & 0.0001 \\
\hline BMI & $\mathrm{AUC}_{0-\infty}$ & Imitrex, 6 mg & 139.610 & -1.311 & 8.320 & 0.0089 & 0.0242 \\
\hline
\end{tabular}

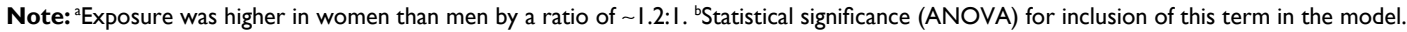
Abbreviations: AUC, area under the curve; BMI, body mass index; $\mathrm{C}_{\max }$, maximum plasma concentration. 
Table 4 Additional effect of race in regression models including weight or BMI (limited to those analyses for which the effect of sex was statistically significant) ${ }^{\mathrm{a}}$

\begin{tabular}{|c|c|c|c|c|c|c|c|}
\hline Weight/BMI & $\begin{array}{l}\text { Exposure } \\
\text { metric }\end{array}$ & Treatment & Intercept & Coefficient (weight/BMI) & Coefficient (race) & $P($ weight/BMI) & $P(\text { race })^{b}$ \\
\hline Weight & $\mathrm{AUC}_{0-2}$ & DFN-II, 3 mg & 64.640 & -0.295 & -3.259 & $<0.000$ I & 0.0241 \\
\hline Weight & $A \cup C_{0-2}$ & Imitrex, $4 \mathrm{mg}$ & 74.769 & -0.302 & -6.116 & 0.0001 & 0.0375 \\
\hline Weight & $A \cup C_{0-\infty}$ & DFN-II, 3 mg & 85.113 & -0.336 & -3.627 & $<0.0001$ & 0.0661 \\
\hline Weight & $A \cup C_{0-\infty}$ & Imitrex, 4 mg & 101.240 & -0.360 & -9.497 & 0.0019 & 0.0381 \\
\hline BMI & $\mathrm{C}_{\max }$ & Imitrex, 4 mg & 90.228 & -1.137 & -10.925 & 0.0178 & 0.0272 \\
\hline BMI & $\mathrm{AUC}_{0-2}$ & DFN-II, 3 mg & 62.933 & -0.758 & -5.102 & $<0.0001$ & 0.0028 \\
\hline BMI & $A \cup C_{0-2}$ & Imitrex, $4 \mathrm{mg}$ & 76.802 & -0.909 & -8.232 & 0.0066 & 0.0162 \\
\hline BMI & $\mathrm{AUC}_{0-2}$ & Imitrex, $6 \mathrm{mg}$ & 114.530 & -1.399 & -8.708 & 0.0002 & 0.0234 \\
\hline BMI & $A \cup C_{0-\infty}$ & DFN-II, 3 mg & 84.843 & -0.924 & -5.690 & $<0.0001$ & 0.0091 \\
\hline BMI & $A \cup C_{0-\infty}$ & Imitrex, $4 \mathrm{mg}$ & 107.650 & -1.231 & -12.333 & 0.0107 & 0.0134 \\
\hline BMI & $A \cup C_{0-\infty}$ & Imitrex, $6 \mathrm{mg}$ & 154.500 & -1.648 & -10.478 & 0.0008 & 0.0360 \\
\hline
\end{tabular}

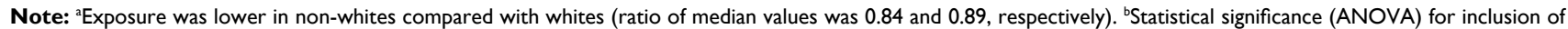
this term in the model.

Abbreviations: AUC, area under the curve; $B M I$, body mass index; $C_{\max }$, maximum plasma concentration.

\section{Effect of BMI}

For most treatment groups, increasing BMI was associated with decreasing sumatriptan exposure (Table 5) for all three metrics $(P<0.05$ [linear regression] for each treatment group within each metric); exceptions were $\mathrm{AUC}_{0-\infty}$ for Imitrex $3 \mathrm{mg}(P=0.052)$ and $\mathrm{C}_{\max }$ for Imitrex $4 \mathrm{mg}(P=0.061)$. Across all treatment groups, $\mathrm{AUC}_{0-2}$ for subjects with BMI less than or equal to median value was 1.03-1.12 times the value for subjects with BMI more than median value. For subjects with BMI less than or equal to median value receiving DFN-11, median $\mathrm{AUC}_{0-2}$ was slightly less than that for subjects with BMI more than median value receiving Imitrex $4 \mathrm{mg}$ and larger than that for subjects with BMI more than median value receiving Imitrex $3 \mathrm{mg}$. $\mathrm{AUC}_{0-\infty}$ for subjects with BMI less than or equal to median value was 1.03-1.15 times the value for subjects with BMI less than or equal to median value. For subjects with BMI less than or equal to median value receiving DFN-11, median $\mathrm{AUC}_{0-\infty}$ was less than that for subjects with BMI more than median value receiving Imitrex $4 \mathrm{mg}$ and larger than that for subjects with BMI more than median value receiving Imitrex $3 \mathrm{mg}$. $\mathrm{C}_{\text {max }}$ for subjects with BMI less than or equal to median value was $1.02-1.14$ times the value for subjects with BMI more than median value. For subjects with BMI less than or equal to median value receiving DFN-11, median $\mathrm{C}_{\max }$ was less than that for subjects with BMI more than median value receiving Imitrex $4 \mathrm{mg}$ and larger than that for subjects with BMI more than median value receiving Imitrex $3 \mathrm{mg}$.

In the multiple regression analyses, after incorporating the effect of BMI, $\mathrm{C}_{\max }$ was $9.0 \mathrm{ng} / \mathrm{mL}$ higher in women with DFN-11, $8.9 \mathrm{ng} / \mathrm{mL}$ higher with Imitrex $4 \mathrm{mg}$, and
$14.8 \mathrm{ng} / \mathrm{mL}$ higher with Imitrex $6 \mathrm{mg}$. $\mathrm{AUC}_{0-2}$ was $3.7-8.6 \mathrm{ng} /$ $\mathrm{mL} \mathrm{h}$ higher in women across the four products. $\mathrm{AUC}_{0-\infty}$ was $6.1 \mathrm{ng} / \mathrm{mL} \mathrm{h}$ higher in women with DFN-11 and $8.3 \mathrm{ng} / \mathrm{mL}$ $\mathrm{h}$ higher with Imitrex $6 \mathrm{mg}$. After incorporating the effect of BMI, $\mathrm{C}_{\text {max }}$ was $10.9 \mathrm{ng} / \mathrm{mL}$ lower in non-Caucasians with Imitrex $4 \mathrm{mg}, \mathrm{AUC}_{0-2}$ was $5.1-8.7 \mathrm{ng} / \mathrm{mL}$ h lower in nonCaucasians for DFN-11 and Imitrex $4 \mathrm{mg}$ and $6 \mathrm{mg}$. $\mathrm{AUC}_{0-\infty}$ was $5.7-12.3 \mathrm{ng} / \mathrm{mL} \mathrm{h}$ lower in non-Caucasians for DFN-11 and Imitrex $4 \mathrm{mg}$ and $6 \mathrm{mg}$.

\section{Effect of age}

There was no relationship between sumatriptan exposure and age.

\section{Sex}

For most treatment groups, sumatriptan exposure in women was higher than in men, the ratio typically being $\sim 1.2$. This ratio results in part from the difference in weight between men and women.

\section{Effect of race}

For DFN-11, $\mathrm{AUC}_{0-2}$ and $\mathrm{AUC}_{0-\infty}$ were lower in non-whites compared with whites; the ratio of median values was 0.84 and 0.89 , respectively. A similar, nonstatistically significant trend was observed in the other products (ratio of median values ranging from 0.84 to 0.892 ).

\section{Safety}

In 98 subjects exposed to $\mathrm{SC}$ sumatriptan, all reported adverse events were among those currently described for marketed sumatriptan products. There were no deaths or related serious adverse events. Only one study (Study 003) included a 
Table 5 Effect of BMI on systemic exposure to sumatriptan.

\begin{tabular}{|c|c|c|c|c|}
\hline \multirow[t]{2}{*}{ Exposure metric } & \multirow[t]{2}{*}{ DFN-I I $3 \mathrm{mg}$} & \multicolumn{3}{|l|}{ Imitrex $^{\otimes *}$} \\
\hline & & $3 \mathrm{mg}$ injection & 4 mg STATdose & $6 \mathrm{mg}$ STATdose or injection \\
\hline $\mathrm{AUC}_{0-2}(\mathrm{ng} / \mathrm{mL} \mathrm{h})$ & $43.35 / 40.03^{a}$ & $39.20 / 37.99^{a}$ & $52.5 \mathrm{I} / 48.6 \mathrm{I}^{\mathrm{a}}$ & $80.14 / 71.38^{\mathrm{a}}$ \\
\hline $\mathrm{AUC}_{0-\infty}(\mathrm{ng} / \mathrm{mL} \mathrm{h})$ & $62.4 \mathrm{I} / 54.76^{\mathrm{a}}$ & $57.23 / 52.46$ & $72.24 / 70.94^{a}$ & $112.22 / 103.22^{\mathrm{a}}$ \\
\hline $\mathrm{C}_{\max }(\mathrm{ng} / \mathrm{mL})$ & $51.2 / 45.2^{\mathrm{a}}$ & $48.1 / 43.65^{\mathrm{a}}$ & $59.45 / 57.90$ & $90.50 / 78.40^{\mathrm{a}}$ \\
\hline
\end{tabular}

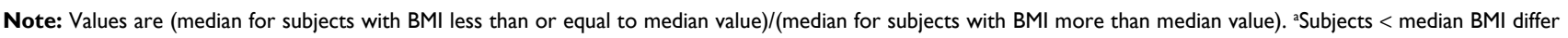
$(P<0.05)$ from those $>$ median BMI by t-test. *Generic name: Sumatriptan.

Abbreviations: $\mathrm{AUC}$, area under the curve; $\mathrm{BMI}$, body mass index; $\mathrm{C}_{\max }$, maximum plasma concentration.

head-to-head comparison of DFN-11 to the two autoinjector products, Imitrex STATdose $4 \mathrm{mg}$ and Imitrex STATdose $6 \mathrm{mg}$. In that study, the incidence of injection site pain with DFN-11 was 39\%, lower than that observed with Imitrex STATdose $6 \mathrm{mg}(53 \%)$ and similar to Imitrex STATdose $4 \mathrm{mg}(42 \%)$. The incidence of injection site erythema with DFN-11 was $28 \%$, higher than with Imitrex STATdose $6 \mathrm{mg}$ (19\%) and similar to Imitrex STATdose $4 \mathrm{mg}$ (25\%). All these events were mild in nature and resolved without medical intervention. The percentage of subjects experiencing at least one adverse event was $56 \%$ for DFN- $11,72 \%$ for Imitrex STATdose $4 \mathrm{mg}$, and $67 \%$ for Imitrex STATdose $6 \mathrm{mg}$.

\section{Discussion}

These post hoc exploratory analyses demonstrate a statistically significant impact of body size, assessed by weight and BMI, on systemic exposure to sumatriptan administered as DFN-11 or Imitrex. For each treatment group, subjects with lower BMI or weight had higher systemic exposure compared with subjects with higher BMI or weight. For both products, exposure was higher in women than in men, with ratios as high as 1.29; this sex effect is largely a function of weight (women weighing less than men).

In addition to evaluating $\mathrm{C}_{\max }$ and $\mathrm{AUC}_{0-\infty}$ as exposure metrics, we evaluated $\mathrm{AUC}_{0-2}$. This metric was selected (and prespecified in the analysis plan) because sumatriptan's efficacy window is typically within the first 2 hours; therefore, systemic exposure during this period is more relevant than systemic exposure well after efficacy is expected to wane.

For continuous covariates, the median value of the covariate was used to divide subjects into two groups; the median value for each metric was then compared between these groups. If the ratio were markedly less than unity, it would suggest that subjects weighing more or having a larger BMI experienced lower exposure for that metric. In turn, it might imply different dosing requirements as a function of that covariate.

These post hoc analyses demonstrate that sumatriptan exposure was higher in lighter subjects and those with BMI less than or equal to the median value. Several studies have reported that body size affects migraine response. Saracco et a ${ }^{6}$ pooled ITT data from 346 subjects in three double-blind, placebo-controlled randomized studies with frovatriptan and other triptans. Pain-free rates at 2 hours were lower in obese subjects $(27 \%)$ compared with nonobese subjects (34\%). Visser et $\mathrm{al}^{7}$ mailed a survey questionnaire to 869 migraine patients, of whom 735 (85\%) replied. To determine risk factors for nonresponders to sumatriptan, the investigators compared clinical characteristics, demographics, and migraine-associated symptoms: non responders to SC sumatriptan had a higher BMI. In a post hoc analysis from a double-blind randomized, placebo-controlled study with rizatriptan $10 \mathrm{mg}$ oral tablets in children aged 12-17 years, weight $<40 \mathrm{~kg}$ was associated with higher pain-free rates $(34.6 \%)$ compared with weight $\geq 40 \mathrm{~kg}$ $(30.2 \%) .{ }^{8}$ One of the limitations of this study was that the sample size for the $<40 \mathrm{~kg}$ group was much smaller than that for the $\geq 40 \mathrm{~kg}$ group ( $26 \mathrm{vs} 258$ ). In contrast, the post hoc analysis of a combination product (sumatriptan $85 \mathrm{mg} /$ aproxen $500 \mathrm{mg}$ ) by Winner et $\mathrm{al}^{9}$ found no correlation between BMI and treatment response. Cosson and Fuseau ${ }^{10}$ demonstrated a relationship between apparent clearance and weight and, consequently, an inverse relationship between AUC and weight. However, these investigators did not report the coefficient of that relationship so we were unable to compare their results with ours.

Two prospective efficacy studies have compared sumatrip$\tan$ SC 3-6 mg. In a pilot study of SC sumatriptan, Landy et $\mathrm{al}^{11}$ reported that subjects preferred $3 \mathrm{mg}$ over $6 \mathrm{mg}$ : $66.7 \%$ of subjects administered $3 \mathrm{mg}$ achieved a combined end point at 2 hours of being pain-free with no significant side effects compared with $50 \%$ of subjects administered with $6 \mathrm{mg}$. The difference between groups was larger at 24 hours: $63.3 \%$ vs $33.3 \%$. Preference for the smaller dose in both studies suggests that larger doses, despite their potential for improved efficacy, may cause adverse effects limiting their utility.

Mathew et al ${ }^{12}$ reported similar 1-hour pain relief rates with $3 \mathrm{mg}(57 \%)$ and $4 \mathrm{mg}(50 \%)$ and a higher rate with 
$6 \mathrm{mg}$ (73\%). Although both studies demonstrate that SC $3 \mathrm{mg}$ provides pain relief to a significant number of migraineurs, major limitations of both are that sample sizes were small (30 subjects per group) and efficacy data were not stratified by BMI. The same study also reported few of certain triptanrelated adverse events - flushing, nausea, tingling, warm/ hot sensation, numbness, and dizziness - with sumatriptan injection $3 \mathrm{mg}$ compared with $6 \mathrm{mg}$. Prospective studies are required to understand if BMI impacts efficacy of lowdose sumatriptan injection or other triptans for episodic migraineurs. In addition, smaller doses may be preferred by certain subgroups of patients if they provide comparable efficacy with fewer adverse effects.

\section{Conclusion}

Weight and BMI appear to be important covariates for sumatriptan exposure: subjects with lower values for either metric of body size have higher systemic exposure compared with subjects with higher values. Additional studies are required to determine if doses of SC sumatriptan may be adjusted based on BMI for comparable efficacy and a potentially improved tolerability profile.

\section{Acknowledgment}

This study was supported and funded by Dr. Reddy's Laboratories Ltd.

\section{Disclosure}

Doctor Sagar Munjal and Anirudh Gautam are employed by and own stock of Dr. Reddy's Laboratories Ltd. Doctor Alan Rapoport serves as a consultant, advisory board member, and/or has received compensation from Autonomic Technologies Inc, Avanir Pharmaceuticals, Depomed Inc, Dr. Reddy's Laboratories, ElectroCore ${ }^{\circledR}$, Impax Laboratories Inc, Pernix Therapeutics, Teva Pharmaceutical Industries, and Zosano Pharma Inc. Doctor Dennis Fisher is a full-time employee of P Less Than and is a paid consultant for Dr. Reddy's Laboratories. The authors report no other conflicts of interest in this work.

\section{References}

1. Buse DC, Loder EW, Gorman JA, et al. Sex differences in the prevalence, symptoms, and associated features of migraine, probable migraine and other severe headache: results of the American Migraine Prevalence and Prevention (AMPP) study. Headache. 2013;53(8):1278-1299.

2. Imitrex ${ }^{\circledR}$ (sumatriptan succinate) injection [prescribing information] [webpage on the Internet]. Research Triangle Park: GlaxoSmithKline. 2015. Available from: https:/gsksource.com/pharma/content/dam/ GlaxoSmithKline/US/en/Prescribing_Information/Imitrex_Injection/ pdf/IMITREX-INJECTION-PI-PPI-PIL-COMBINED.PDF. Accessed October 24, 2015.

3. Imitrex ${ }^{\circledR}$ (sumatriptan succinate) tablets [prescribing information] [webpage on the Internet]. Research Triangle Park: GlaxoSmithKline. 2015. Available from: https://www.gsksource.com/pharma/content/dam/ GlaxoSmithKline/US/en/Prescribing_Information/Imitrex_Tablets/pdf/ IMITREX-TABLETS-PI-PIL.PDF. Accessed October 24, 2015.

4. Imitrex ${ }^{\circledR}$ (sumatriptan succinate) nasal spray [prescribing information] [webpage on the Internet]. Research Triangle Park: GlaxoSmithKline. 2015. Available from: https://www.gsksource.com/pharma/content/ dam/GlaxoSmithKline/US/en/Prescribing_Information/Imitrex_Nasal_ Spray/pdf/IMITREX-NASAL-SPRAY-PI-PIL.PDF. Accessed October 24, 2015.

5. Moore KH, Hussey EK, Shaw S, Fuseau E, Duquesnoy C, Pakes GE. Safety, tolerability, and pharmacokinetics of sumatriptan in healthy subjects following ascending single intranasal doses and multiple intranasal doses. Cephalalgia. 1997;17(4):541-550.

6. Saracco MG, Allais G, Tullo V, et al. Efficacy of frovatriptan and other triptans in the treatment of acute migraine of normal weight and obese subjects: a review of randomized studies. Neurol Sci. 2014;35(suppl 1): S115-S119.

7. Visser WH, de Vriend RH, Jaspers NH, Ferrari MD. Sumatriptannonresponders: a survey in 366 migraine patients. Headache. 1996;36(8): 471-475.

8. United States Food and Drug Administration [webpage on the Internet]. Clinical Pharmacology Review for MAXALT-MLT ${ }^{\mathbb{B}} ; 2$ 2011. Available from: http://www.fda.gov/downloads/drugs/developmentapprovalprocess/developmentresources/ucm289415.pdf. Accessed October 24, 2015.

9. Winner PK, Brandes JL, Lener SE, Derosier F, White J, McDonald SA. Evaluation of the relationship body mass index (BMI) to response and tolerability after treatment with a single fixed-dose tablet of sumatriptan $85 \mathrm{mg}$ formulated with RT technology/naproxen sodium $500 \mathrm{mg}$ (SumaRT/ Nap) for the acute treatment of migraine. Presented at the $50^{\text {th }}$ Annual Scientific Meeting of the American Headache Society (Poster S19). Headache. 2008;48(suppl 1):S47.

10. Cosson VF, Fuseau E. Mixed effect modeling of sumatriptan pharmacokinetics during drug development: II. From healthy subjects to phase 2 dose ranging in patients. J Pharmacokinet Biopharm. 1999;27(2): 149-171.

11. Landy SH, McGinnis JE, McDonald SA. Pilot study evaluating preference for 3-mg versus 6-mg subcutaneous sumatriptan. Headache. 2005; 45(4):346-349.

12. Mathew NT, Dexter J, Couch J, et al. Dose ranging efficacy and safety of subcutaneous in the acute treatment of migraine. Arch Neurol. 1992; 49(12):1271-1276.
Clinical Pharmacology: Advances and Applications

Publish your work in this journal

Clinical Pharmacology: Advances and Applications is an international, peer-reviewed, open access journal publishing original research, reports, reviews and commentaries on all areas of drug experience in humans. The manuscript management system is completely online and includes a very quick and fair peer-review system, which is all easy to use.

\section{Dovepress}

Visit http://www.dovepress.com/testimonials.php to read real quotes from published authors. 